NBER WORKING PAPER SERIES

THE APPEALS PROCESS AND ADJUDICATOR INCENTIVES

\author{
Steven Shavell \\ Working Paper 10754 \\ http://www.nber.org/papers/w10754
}

NATIONAL BUREAU OF ECONOMIC RESEARCH

1050 Massachusetts Avenue

Cambridge, MA 02138

September 2004

I would like to thank Lucian Bebchuk, Andrew Daughety, Bert Huang, Louis Kaplow, Daniel Klerman, A. Mitchell Polinsky, Jennifer Reinganum, and seminar participants at Gerzensee and NBER for comments, and the John M. Olin Center for Law, Economics, and Business at Harvard Law School for research support. The views expressed herein are those of the author(s) and not necessarily those of the National Bureau of Economic Research.

C2004 by Steven Shavell. All rights reserved. Short sections of text, not to exceed two paragraphs, may be quoted without explicit permission provided that full credit, including (C) notice, is given to the source. 
The Appeals Process and Adjudicator Incentives

Steven Shavell

NBER Working Paper No. 10754

September 2004

JEL No. D8, K41

\begin{abstract}
The appeals process -- whereby litigants can have decisions of adjudicators reviewed by a higher authority -- is a general feature of formal legal systems (and of many private decisionmaking procedures). It leads to the making of better decisions, because it constitutes a threat to adjudicators whose decisions would deviate too much from socially desirable ones. Further, it yields this benefit without absorbing resources to the extent that adjudicators can anticipate when appeals would occur and would thus make decisions to forestall the actual occurrence of appeals.

Steven Shavell

Harvard Law School

1575 Massachusetts Avenue

Hauser Hall 508

Cambridge, MA 02138

and NBER

shavell@law.harvard.edu
\end{abstract}




\title{
THE APPEALS PROCESS AND ADJUDICATOR INCENTIVES
}

\author{
Steven Shavell ${ }^{*}$ \\ (C2004. Steven Shavell. All rights reserved.
}

\section{Introduction}

This article develops the point that the ability of litigants to appeal decisions of adjudicators to a higher authority may lead to the making of better decisions because the appeals process constitutes a threat to adjudicators whose decisions would deviate too much from socially desirable ones. The appeals process is a feature of virtually all formal legal systems, of many private dispute resolution arrangements (such as those of trade associations and religious organizations), and also of certain decisionmaking procedures within firms, so its relevance is broad. ${ }^{1}$ Indeed, whenever a person might be affected by a deviant action of an agent and would be led to report it credibly to the principal, one might consider an appeals process of a sort to be at work. The appeals process can thus be conceived as a general way to mold the behavior of an agent to a principal's benefit. $^{2}$

\footnotetext{
* Harvard Law School and NBER. I would like to thank Lucian Bebchuk, Andrew Daughety, Bert Huang, Louis Kaplow, Daniel Klerman, A. Mitchell Polinsky, Jennifer Reinganum, and seminar participants at Gerzensee and NBER for comments, and the John M. Olin Center for Law, Economics, and Business at Harvard Law School for research support.

${ }^{1}$ On the appeals process in formal legal systems worldwide, see generally Herzog and Karlen (1982) and Platto (1992); on the appeals process in administrative agencies and in private organizations, see, for example, Mertens (1994), sections 49B.45-53, Scott (1965), chapter 3, and Weiler and Roberts (1993), p. 667.

${ }^{2}$ Nevertheless, I generally refer to the context of legal adjudication in this article; but see the concluding remarks on the broader view.
} 
In section 2, I study a basic model in which there is a socially correct decision, an adjudicator may obtain a benefit from choosing a different decision, and each of two opposing litigants has the right to appeal a decision to an appeals court, at a cost.

Because the adjudicator can anticipate that a decision would be appealed if its deviation is large enough to outweigh the cost of an appeal to a litigant, the adjudicator will be led to keep his deviations below the point at which appeals would be provoked. Thus, the appeals process induces decisions to conform to socially desirable decisions, at least within the range governed by the cost of an appeal. Furthermore, the appeals process yields this benefit without absorbing resources, as the appeals process does not actually result in appeals (although, as will be discussed, appeals do occur in an extension of the basic model where adjudicators are uncertain whether appeals will be made ${ }^{3}$ ). Hence, when the appeals process results in changes in adjudicator behavior, it raises social welfare.

To better appreciate the virtue of the appeals process, it is compared in section 3 to a natural alternative, namely, random monitoring of adjudicators’ decisions. Random monitoring of decisions can also induce adjudicators to conform their decisions to socially desirable decisions. But for monitoring to be effective, a positive degree of monitoring must actually occur. Thus, unlike the appeals process, random monitoring absorbs resources. The cost advantage of the appeals process over random monitoring (which may well exist even when the appeals process does result in appeals, due to uncertainty) reflects what may be regarded as a distinctive feature of the appeals process:

\footnotetext{
${ }^{3}$ Another reason that the appeals process may absorb resources is that society may need to invest some amount in appeals courts in order that the threat of appeal be credible to adjudicators.
} 
that it harnesses the information that litigants possess about decisions and thus leads to review of decisions only if they deviate from socially desirable decisions.

In section 4, a series of extensions of the basic model is considered. The first concerns subsidy of the appeals process. Here it is explained that a subsidy is beneficial (and that the optimal subsidy is complete) since, on one hand, it increases the threat of appeal and thus makes adjudicator decisions better reflect socially desirable ones, and, on the other hand, a subsidy does not lead to greater social costs since appeals do not actually occur.

The second extension relates to contexts in which only a single litigant can make an appeal (such as individuals contesting benefit awards by the Social Security Administration). Here the effectiveness of the appeals process is reduced relative to what it is when there are opposing litigants, since any decision that is favorable to the single litigant will not be appealed; the appeals process functions only to discipline unfavorable decisions to the litigant.

The third extension addresses the possibility that a litigant who would want to make an appeal could instead settle with the opposing litigant, in order to save the joint costs of an appeal. Although a litigant who could bring an appeal would have a motive to settle, the adjudicator would still want to avoid decisions that would provoke appeal, for the adjudicator would not want the accompanying settlement to occur. Therefore, the adjudicator's decision turns out to be the same as when settlement of appeals is not considered as a possibility.

The fourth extension allows for multiple levels of appeal. It is shown that decisions at each level are implicitly guided by the preferences of all higher levels, 
including the topmost, say the $\mathrm{n}^{\text {th }}$, level of appeal, because decisions at the $\mathrm{n}-1^{\text {st }}$ level of appeal will reflect judicial preferences at the $n^{\text {th }}$ level, decisions at the $n-2^{\text {nd }}$ level of appeal will reflect decisions that would be made at the $n-1^{\text {st }}$ level, and so on. In this way, judicial preferences at the highest level of appeal are translated all the way down to the adjudicator at the trial court level. However, the transmission of judicial preferences is not perfect; in particular, trial court decisions may differ from those preferred by the highest appeals court by as much as the sum of the costs of appeal across the different levels of appeal.

The fifth extension concerns uncertainty about the outcome of an appeal. When parties are uncertain what the socially desirable decision that would be found by the appeals court would be, the appeals process leads adjudicators to conform their decisions to the expected appeals court decision rather than to the actual, socially preferred decision. This renders the appeals process less valuable than when appeals court decisions are accurately foreseen and may make the appeals process socially undesirable. A corollary to this point, with a very different interpretation, is also noted. Suppose that uncertain appeals courts decisions are not presumed to be socially desirable (whereas they are assumed so immediately above) but that they are socially desirable on average. Then adjudicators who are uncertain about appeals court decisions will make decisions as if appeals courts always make the social desirable decision.

The sixth extension involves uncertainty about whether an appeal will be made. When adjudicators are uncertain whether litigants will make an appeal, adjudicator decisions will sometimes not forestall appeals, and appeals will in fact occur. This 
means, among other things, that the appeals process becomes socially costly, and may not be socially worthwhile.

The last extension examines the possibility of granting discretion to appeals courts to decide whether or not to hear cases that have been appealed. Giving appeals courts such discretion offers a potential social cost-saving advantage: a litigant may wish to make an appeal even though the social cost of an appeal outweighs the social benefit, so that refusal by the appeals court to consider an appeal may be socially beneficial. Yet discretion is not necessarily socially desirable, because it reduces the threat of appeal to the adjudicator, and hence his motive to make his decisions resemble those of the appeals court.

The point of this article, that the appeals process influences the decisions of adjudicators because they want to avoid appeal, is a common theme in a general qualitative sense in legal literature, ${ }^{4}$ but has not been much developed to my knowledge in economically-oriented literature. However, particular aspects of the effect of the appeals process on adjudicator behavior have been examined by economists: Levy (2003) focuses on the tendency of judges to provoke appeal, so as to signal that they are talented and to benefit from an enhanced reputation; and Iossa and Palumbo (2004) emphasize the role of the appeals process in a comparison of the adversarial and inquisitorial methods of acquisition of evidence. Also, a number of articles on appeals investigate factors other than control of adjudicator behavior. Shavell (1995) and Cameron and Kornhauser (2004) study how the appeals process functions to correct lower court errors (as opposed to preventing them, the subject of this article); Spitzer and Talley (2000), and Daughety

\footnotetext{
${ }^{4}$ See for example, Dalton (1985) and Pound (1941), p. 3.
} 
and Reinganum (2004) analyze the exercise of discretion by appeals courts over whether to review lower court decisions; and Daughety and Reinganum (2000) stress inference by appeals courts about superior courts from the fact that appeals are brought. 


\section{Basic Model}

The basic model is described by the following simple timeline.

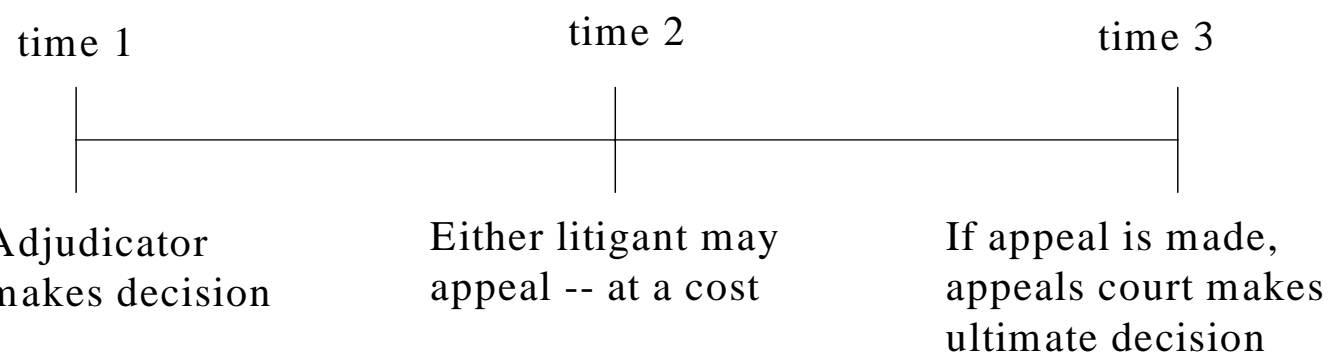

As the timeline indicates, an adjudicator makes an initial decision. This decision - or, rather, whatever is the ultimate decision - affects the adjudicator's utility (he might have his own idea of what constitutes a proper decision, or have private interests in the decision $^{5}$ ). The decision also affects social welfare and litigants' utilities. Let

\footnotetext{
${ }^{5}$ An adjudicator might have a personal view of social welfare and care about it. Also, an adjudicator might have a private interest in a decision because he is bribed or threatened. In the context of decisionmaking within a firm, say that of a supervisor (an adjudicator) about the promotion of an employee (a litigant, who could appeal a negative decision to another person in the firm), the supervisor's utility would not necessarily align with the firm's; his utility from the promotion decision would tend to depend on how the employee's performance would relate to the promotion decision and in turn on how the employee's performance would affect the supervisor's remuneration.
} 


$$
\begin{aligned}
d & =\text { adjudicator's decision; } d \text { is a real number; } \\
u(d) & =\text { utility of the adjudicator; } \\
w(d) & =\text { social welfare; } \\
d & =\text { utility of litigant } 1 \\
-d & =\text { utility of litigant } 2
\end{aligned}
$$

The functions $u$ and $w$ are assumed to be differentiable and strictly concave. ${ }^{7}$ Note that the litigants have opposing interests in the decision $d .^{8}$

Let $d^{*}$ be the adjudicator's preferred decision and $d_{S} *$ be the socially optimal decision, and assume that $d^{*}$ is unequal to $d_{S} *$ (this is the case of interest).

As the timeline also indicates, a litigant is presumed to be able to make an appeal to an appeals court at a cost; an appeal is assumed to involve a cost to defend on the part of the opposing litigant as well.

If an appeal is made, the appeals court is assumed to set the adjudicator's decision equal to the socially optimal one $d_{S} *$ if the decision deviated from $d_{S} *$. In other words, the appeals court is implicitly assumed to have social welfare $w(d)$ as its utility function, ${ }^{9}$

\footnotetext{
${ }^{6}$ The decision $d$ might be interpreted as the amount that one litigant is required to pay the other (possibly zero if no liability is found).

${ }^{7}$ The assumption of strict concavity guarantees that there is a unique optimal decision and that the closer a decision is to the optimal one, the better. The importance of the assumption is noted at the end of this section.

${ }^{8}$ The results to be obtained would be qualitatively similar if instead it were assumed that litigant 1 has a utility function $v_{1}(d)$ that is monotonically increasing in $d$ and that litigant 2 has a utility function $v_{2}(d)$ that is monotonically decreasing in $d$.

${ }^{9}$ The case in which the appeals court has a different utility function from society's is discussed at the end of this section, in sections 4.4 and 4.5 , and in the first concluding remark.
} 
so that, when presented with an appeal, it maximizes $w(d) .{ }^{10}$ It is also assumed that if the adjudicator's decision differed from $d_{S} *$ a reversal penalty is imposed on the adjudicator.

Define

$$
\begin{aligned}
& c=\text { cost to a litigant of making or of opposing an appeal; } c>0 ;^{11} \\
& r=\text { reversal penalty imposed on the adjudicator if } d \text { is unequal to } d_{S} * ; r \geq 0 .{ }^{12}
\end{aligned}
$$

If an appeal is made and $d$ is unequal to $d_{S}^{*}$, the adjudicator's utility will thus be $u\left(d_{S}{ }^{*}\right)-$ $r$; his utility overall is assumed to be separable in $r$. Additionally, if an appeal is made, social welfare will be $w\left(d_{S}^{*}\right)-2 c$; social welfare is assumed to be separable in litigation costs.

Adjudicators are assumed to know $c, r$, and $d_{S} *$. Litigants are assumed to know $c$ and $d_{S} *$.

Under these assumptions, an appeal of a decision $d$ will be made by litigant 1 when $d_{S}{ }^{*}-c>d$, since the left side is what the litigant would obtain if there were an appeal and the right side is what he would obtain otherwise. ${ }^{13}$ Likewise, an appeal will be made by litigant 2 when $d>d_{S} *+c{ }^{14}$ Thus the set of decisions for which appeals would not be made is $d$ in

${ }^{10}$ This presumes that the appeals court cannot commit to a different decision from $d_{S} *$; see the end of this section on why the appeals court would want to commit to a different decision. inessential.

11 The assumption that the cost of making the appeal and of opposing the appeal are the same is

${ }^{12}$ In reality, $r$ may be to an extent exogenous, because it may include a reputational loss to an adjudicator, and $r$ might also in principle depend on the difference between $d$ and $d_{s} *$. In any case, the magnitude of $r$ does not matter in the basic model or in most of the extensions, as it will turn out that appeals not occur. The magnitude of $r$ does matter in section 4.6, however, because appeals do occur there.

${ }^{13} \mathrm{I}$ am assuming that if the litigant is indifferent, he will not bring an appeal, and make similar assumptions below without comment.

${ }^{14}$ I am implicitly assuming that, if one of the parties would wish to make an appeal, there is no settlement with the opposing party. Settlement is discussed in section 4.3. 


$$
N=\left[d_{S}^{*}-c, d_{S}^{*}+c\right] .
$$

Note that the adjudicator knows $N$ as he knows $c$ and $d_{S}{ }^{*}$.

Let us describe the decision $d^{* *}$ that the adjudicator actually makes. The adjudicator will select a decision in $N$. If he does not do so, there will be an appeal and he will obtain utility of $u\left(d_{s}^{*}\right)-r$, whereas he could always guarantee that he is at least as well off by choosing $d_{S}^{*}$, an element of $N$, in which case he would obtain $u\left(d_{S}^{*}\right)$. Indeed, the adjudicator must be strictly better off by choosing a decision in $N$ : if $r>0$, he is strictly better off merely choosing $d_{s}^{*}$; and even if $r=0$, he must still be strictly better off, since either a slightly higher or slightly lower $d$ than $d_{S} *$ must increase his utility (for $u$ must be strictly monotonic in $d$ at $d_{S} *$ since $d_{S} *$ does not maximize $u$ and $u$ is strictly concave), which can be chosen so as to be in $N$. We thus know that the adjudicator will select $d$ to maximize his utility in $N$. In particular, if $d^{*}$ is in $N$, he will obviously choose $d^{*}$. If $d^{*}$ is to the left of $N$, he will choose its left end point $d_{S}^{*}-c$ (since $u$ is strictly concave). Similarly, if $d^{*}$ is to the right of $N$, he will choose $d_{S}{ }^{*}+c$.

We may summarize as follows.

Proposition 1. (a) The adjudicator's decision $d^{* *}$ is the personally best decision in the set $N=\left[d_{s} *-c, d_{S}^{*}+c\right]$ that forestalls appeals, so that appeals never in fact occur.

(b) If the unconstrained best choice $d^{*}$ of the adjudicator would not result in an appeal, the adjudicator's choice $d^{* *}$ is $d^{*}$. Otherwise, the adjudicator chooses the closest end point of $N\left(d^{* *}\right.$ is either $d_{S}^{*}-c$ or $\left.d_{S}^{*}+c\right)$, a decision that barely forestalls appeals.

(c) The adjudicator's decision $d^{* *}$ differs from the socially optimal decision $d_{S}^{*} . / /$ 
It should be noted that, the smaller the set $N$, the closer will be the induced decision $d^{* *}$ of the adjudicator to $d_{S}^{*}$; hence, the lower is the cost $c$ of an appeal, the closer must be the adjudicator's decision to $d_{S}{ }^{*}$. Also, as explained in the proof, the penalty $r$ for reversal plays no role in adjudicator behavior; regardless of the magnitude of $r$ (even if it is zero), the adjudicator will choose a decision in $N$, so that $r$ is irrelevant for him.

The next proposition states that the appeals process can only enhance social welfare.

Proposition 2. If the appeals process leads the adjudicator to alter his decision (that is, if $d^{* *}$ is unequal to $d^{*}$, because $d^{*}$ lies outside $N$ ), social welfare rises.//

This result follows because, from Proposition 1(b), we know that when $d^{*}<d_{S}{ }^{*}-$ $c$, the adjudicator chooses $d_{S}{ }^{*}-c$. Since $w$ is strictly concave, social welfare must be increasing in $d$ to the left of $d_{S}{ }^{*}$ and hence social welfare must be higher at $d_{S}{ }^{*}-c$ than at $d^{*}$. Similarly, since when $d^{*}>d_{S}^{*}+c$, the adjudicator chooses $d_{S}^{*}+c$, social welfare must be higher at $d_{S}^{*}+c$. Moreover, since no appeals are actually made, social welfare does not fall from $c$ actually being incurred by each litigant.

Before continuing, several comments about this section are worth making. First, it was assumed that the appeals court maximizes social welfare $w(d)$ in any case that comes before it, so chooses $d_{S}^{*}$. If, though, the appeals court could commit to a decision, the appeals court would generally choose a different decision because it could then induce the adjudicator to choose $d_{S}{ }^{*}$ (rather than a different decision, either $d^{*}, d_{S}{ }^{*}-$ $c$, or $d_{S}^{*}+c$ ). Specifically, if the adjudicator's preferred decision $d^{*}$ is less than $d_{S}^{*}$, let the appeals court commit to $d_{S} *+c$. Then $N=\left[d_{S} *+c-c, d_{S} *+c+c\right]=\left[d_{S}^{*}, d_{S} *+\right.$ 
$2 c$ ], and by the logic of Proposition 1, the adjudicator would select $d_{S}^{*}$. Likewise, if $d^{*}>$ $d_{S}{ }^{*}$, then provided that the appeals court commits to $d_{S}{ }^{*}-c, N=\left[d_{S} *-2 c, d_{S} *\right]$ and the adjudicator would again select $d_{S}{ }^{*}$. The assumption that the appeals court cannot commit to a decision different from $d_{S} *$ might fit if, as seems to be true, appeals courts must adhere to legal principles; for to commit to a different decision from $d_{S} *$ might openly contravene the legal principles they are supposed to follow.

Second, it was assumed that the appeals court's utility function is the social one, $w(d)$. If its utility function is different, say $h(d)$, then of course all that was said above would just be reinterpreted to apply to $h(d)$; that is, $d_{S}{ }^{*}$ would be replaced by $d_{h}{ }^{*}$, where $d_{h}{ }^{*}$ is the decision that maximizes $h(d)$, and so forth. See also sections 4.4 and 4.5 and the concluding remarks on the situation where the appeals court's utility function is not society's.

Third, suppose that one considers a general version of the basic model, in which the set of possible decisions of the adjudicator could be of an arbitrary nature and no restrictions would be placed on $u$ and $w$ and the litigant's utilities from decisions. In such a general model, Proposition 1(a) would continue to hold: the argument that the adjudicator chooses a decision that forestalls appeal, and thus that appeals do not occur, would still apply, as it depends only on the assumption that the adjudicator can predict when appeals would be made. Proposition 1(b) would not hold, however, because the adjudicator might not select a decision on the boundary of $N$ (and $N$ might not have a boundary); and Proposition 1(c) would not hold, because the adjudicator might choose 
$d_{S} *{ }^{15}$ Also, Proposition 2 would not hold, because the change in the adjudicator's decision might turn out to lower social welfare. ${ }^{16}$

\section{Appeals Process versus Random Monitoring}

To gain understanding about the appeals process, it is useful to compare it to random monitoring of adjudicators' decisions, under which a sanction would be imposed on the adjudicator if his decision deviated from the socially optimal decision. Suppose that

$$
\begin{aligned}
& p=\text { probability that the adjudicator's decision } d \text { is monitored; } \\
& k=\text { sanction if } d \text { deviates from the socially optimal decision } d_{S}{ }^{*}{ }^{17} k>0 ; \\
& m=\text { social cost of monitoring; } m>0 .
\end{aligned}
$$

The amount $m$ must be expended in order for the decision of the adjudicator to be observed by the social authority. Hence, the expected cost of monitoring is pm.

If the adjudicator decides not to choose $d_{S} *$ he will choose $d^{*}$. Hence, he will be led to choose $d_{S} *$ if

$$
u\left(d_{S}^{*}\right) \geq u\left(d^{*}\right)-p k
$$

If $p k$ is not large enough to satisfy (2), so that monitoring has no effect on adjudicator behavior, then monitoring is inferior to the appeals process. In particular, under monitoring, social welfare is $w\left(d^{*}\right)-p m$, whereas under the appeals process social

\footnotetext{
${ }^{15}$ For example, suppose that the assumptions are as in the model but that $u$ is not concave. Then $u$ could have a local maximum in the interior of $N$, and this local maximum could be at $d_{S} *$.

${ }^{16}$ For example, suppose that the assumptions are as in the model but that $w$ is not concave. Suppose also that $d^{*}<d_{S} *-c$ and that $w$ has a local maximum at $d^{*}$, where $w\left(d^{*}\right)$ is such that $w\left(d_{S}^{*}\right)-$ $w\left(d^{*}\right)=\epsilon$ for a small $\epsilon$. The appeals process would result in the adjudicator choosing $d_{S} *-c$, but $w\left(d_{S}{ }^{*}-\right.$ $c)<w\left(d^{*}\right)$ if $\epsilon$ is sufficiently small, so the appeals process would lower social welfare.

${ }^{17}$ The variables $p$ and $k$ are taken as fixed, although they would be optimally chosen in a more general model, along the lines in Becker (1968). In such a model, the sanction $k$ would be maximal (assuming that adjudicators are risk neutral) and $p$ would be lower than if $k$ were not maximal, but the qualitative nature of the conclusions to be discussed below would be unaffected.
} 
welfare is at least $w\left(d^{*}\right)$; monitoring is worse since it absorbs resources, whereas the appeals process is costless as appeals are never made.

If $p k$ is large enough so that (2) is satisfied, then monitoring may or may not be superior to the appeals process. Under monitoring, social welfare is $w\left(d_{s}^{*}\right)-p m$. Under the appeals process, social welfare is $w\left(d^{* *}\right)$ (which is either $w\left(d^{*}\right), w\left(d_{S}^{*}-c\right)$, or $w\left(d_{S}^{*}\right.$ $+c$ ), which is less than $w\left(d_{S} *\right)$. Hence, the appeals process is superior to monitoring if $w\left(d^{* *}\right)>w\left(d_{S}^{*}\right)-p m$, or if (3) $\quad w\left(d_{S}^{*}\right)-w\left(d^{* *}\right)<p m$, that is, if the loss due to the deviation from optimal decisions under the appeals process is less than the expected monitoring expense.

The following proposition states the conclusions that we have reached about monitoring.

Proposition 3. Monitoring of adjudicators' decisions results in socially desirable decisions if the probability of monitoring is sufficiently high. When monitoring does induce socially desirable decisions, it may or may not be superior to the appeals process (which does not induce socially optimal decisions).//

It should be remarked that the cost advantage of the appeals process over monitoring, namely, that under monitoring a positive expected cost must be incurred, derives from the fact that, as stated in the introduction, the appeals process uses the information that the litigants naturally possess about decisions. This means that, under the appeals process, there can be a threat of review that is conditioned on whether the decision deviates from the socially desirable one. Under monitoring, in contrast, the threat of review cannot be conditioned on the decision since the decision is not observed; 
hence, to affect adjudicator behavior monitoring must occur regardless of adjudicators'

decisions. In effect, the appeals process involves monitoring from below by an informed party, rather than monitoring from above by an uninformed party.

\section{Extensions of the Basic Model}

Let us now consider (separately) a number of extensions of the basic model of the appeals process.

4.1 Subsidy of appeals. Suppose that appeals are subsidized by an amount $s$, where $s \leq c$, so that the private cost to a litigant of an appeal is $c-s$. Proposition 1 then applies, with $c-s$ playing the role of $c$. Hence, the set of decisions that do not result in appeals becomes

$$
N=\left[d_{S}^{*}-(c-s), d_{S}^{*}+(c-s)\right] .
$$

If the appeals process without subsidy results in a change in the adjudicator's decision, then the greater the subsidy of the appeals process, the greater the change in the adjudicator's decision and the greater the increase in social welfare. This is so since, by Proposition 1(b), if $d^{*}<d_{S}^{*}-c$, then $d^{*}<d_{S}^{*}-(c-s)$, and by Proposition 1(b), the adjudicator will choose $d_{S} *-(c-s)$, which must further increase social welfare since $w$ is strictly concave. Likewise, if $d^{*}>d_{S}^{*}+c$, the adjudicator will choose $d_{S} *+(c-s)$, which will further increase social welfare. Note too that, since appeals are not actually made, there is no cost associated with $c$ being incurred by litigants. Hence, social welfare increases as $s$ increases. When $s=c$, the subsidy is complete, $N=\left\{d_{s} *\right\}$, and the socially optimal outcome $d_{S} *$ results. In summary, we have

Proposition 4. If the appeals process alters the adjudicator's decision, then subsidizing appeals raises social welfare even more, and the greater the subsidy, the 
greater the increase in social welfare. If the subsidy is complete, the socially optimal outcome $d_{S} *$ results.//

Observe as well that if the subsidy is sufficiently high, the appeals process must be superior to random monitoring of decisions; for (3) will be satisfied if $s$ is close enough to $c$.

4.2 Only a single litigant can make an appeal. Although the case of two litigants who can each make an appeal is typical in litigation, contexts exist in which only one party can make an appeal. For example, only the accused, not the prosecution, can ordinarily make an appeal in a criminal matter. ${ }^{18}$ Also, there are venues, such as in benefits proceedings of the Social Security Administration or in a promotion decision within a firm, where there is often effectively only a single litigant (the person who would receive benefits or obtain a promotion), so this is the only party who can make an appeal.

If there is just one litigant, with, say, utility of $d$ (the other case is clearly essentially identical), the no appeal set is $N=\left[d_{S}^{*}-c, \infty\right)$. The set $N$ is larger than in the basic model, since there is no opposing litigant who would appeal decisions in $\left(d_{S}{ }^{*}+c\right.$, $\infty$ ). This renders the appeals process less valuable as a method of controlling adjudicators' decisions. In other words, we have

Proposition 5. Where there is only one litigant who can make an appeal, the appeals process fails to alter adjudicator decisions if they would favor that litigant. Thus, the appeals process may have lower social value than where there are two opposing litigants.//

${ }^{18}$ On the inability of the prosecution to make an appeal in a criminal proceeding (except in respect to certain issues regarding sentencing), see Stith (1990). 
4.3 Settlement of appeals. It was assumed in the basic model that a litigant would make an appeal if doing so would be worth his while. However, whenever a litigant would wish to make an appeal, it would be mutually beneficial for him and the opposing litigant to settle, in order to save the litigation costs associated with an appeal.

To elaborate, suppose that both of the litigants know each other's litigation costs, so know whether either would have a credible threat to make an appeal. Given this assumption of symmetric information, it will be presumed that the litigants would make a settlement agreement if and only if there would otherwise be an appeal, where the agreement would divide in some way the surplus of $2 c$ of litigation costs from the settlement. ${ }^{19}$ Since an appeal would result in a decision $d_{S}{ }^{*}$ and yield litigant $1 d_{S}{ }^{*}-c$ and cost litigant $2 d_{S} *+c$, the settlement $s$ would be for an amount in the interval $\left[d_{S}{ }^{*}-\right.$ $\left.c, d_{S}{ }^{*}+c\right]$, which is to say, $s$ would be in $N$. But we know from Proposition 1 that the adjudicator would be at least as well off choosing his most preferred element of $N$ than to have the litigants effectively choose an element of $N$ through settlement. Hence, the adjudicator would select the $d$ in $N$ as described in Proposition 1. Our conclusion, therefore, is

Proposition 6. If litigants are able to settle appeals, adjudicators will be led to behave exactly as described in Proposition 1. In particular, adjudicators will choose decisions that forestall appeals - and thus that forestall settlements as well.//

A comment should also be made about the possibility of settlement of the case before it is ever adjudicated (as distinct from after it is adjudicated, in lieu of an appeal). Since such a settlement would reflect the adjudicator's decision, and since this would be

\footnotetext{
${ }^{19}$ Of course, if it were assumed that the first litigant makes a single offer to the second, the first litigant would capture the entire surplus; there is no reason to be explicit about the nature of bargaining for present purposes.
} 
$d^{* *}$, the effect of the threat of appeal on adjudicator behavior would influence settlements in the first place.

4.4 Multiple levels of appeal. Suppose here that there are $n$ levels of appeal, instead of just the single level of appeal in the basic model. Then the adjudicator's decision will be implicitly influenced by all the levels of appeal, and will be centered on the preferences of the top-most appeals court, as indicated in the introduction.

Let $u_{i}(d)$ be the utility function of the $i^{\text {th }}$ court level and $d_{i} *$ be the preferred unconstrained choice of the court at level $i$, where $i=0$ is the trial court level, $i=1$ is the first level of appeal, and $i=n$ is the highest level of appeal. Assume as well that $u_{n}(d)=$ $w(d)$, that is, the highest level appeals court has society's preferences. Suppose that $c_{i}$ is the cost to each litigant of making or defending an appeal at stage $i$, where $i=1, \ldots, \mathrm{n}$. Further, suppose that litigants know the utility functions $u_{i}(d)$ of the courts at all levels of appeal and that the appeals courts know these as well as the $c_{i}$. Thus, the assumptions are generalizations of those made in the basic model with one level of appeal.

To determine adjudicator behavior is straightforward. If the $n^{\text {th }}$ level appeals court were to decide a case, it would choose $d_{S}{ }^{*}$, as there is no court above it. Consequently, the $n-1^{\text {st }}$ level court would be in a position that is analogous to that of the adjudicator in the basic model: this court would choose the decision that maximizes its utility $u_{n-1}(d)$ in the set that forestalls appeals at level $n$, namely, $N(n)=\left[d_{S} *-c_{n}, d_{S} *+\right.$ $c_{n}$ ]. Let the decision of $n-1^{\text {st }}$ appeals court be designated $d_{n-1} * *$. By the logic of Proposition $1, d_{n-1} * *=d_{S} *-c_{n}$ if $d_{n-1} *<d_{S} *-c_{n} ; d_{n-1} * *=d_{n-1} *$ if $d_{n-1} *$ is in $N(n)$; and $d_{n-1} * *=d_{S} *+c_{n}$ if $d_{n-1} *>d_{S} *+c_{n}$. By induction, if the $n-j^{\text {th }}$ level court hears a case, it would choose the decision that maximizes $u_{n-j}(d)$ in $N(n-j+1)=\left[d_{n-j+1}{ }^{* *}-\right.$ 


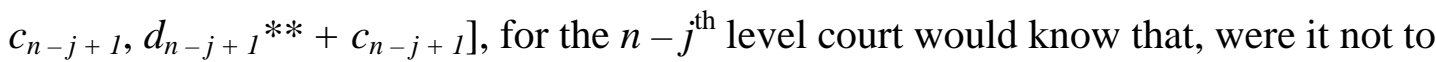
forestall appeals, the $n-j+1^{\text {st }}$ level decision $d_{n-j+1}{ }^{* *}$ would be the final decision (since that court would choose a decision that would forestall appeals). Consequently,

$$
\begin{aligned}
& d_{n-j+1} * *-c_{n-j+1} \text { if } d_{n-j} *<d_{n-j+1} * *-c_{n-j+1} \\
d_{n-j} * *=\quad & d_{n-j} * \text { if } d_{n-j} * \text { is in } N(n-j+1) \\
& d_{n-j+1} * *+c_{n-j+1} \text { if } d_{n-j} *>d_{n-j+1} * *+c_{n-j+1} .
\end{aligned}
$$

It follows from (5) that the initial adjudicator's decision $d_{0} * *$ is in $N(1)=\left[d_{1} * *-c_{1}, d_{1} * *\right.$ $+c_{1}$ ], where $d_{0}{ }^{* *}=d_{1}^{* *}-c_{1}$ if $d_{0}^{*}<d_{1}^{* *}-c, d_{0}^{* *}=d_{0}^{*}$ if $d_{0}^{*}$ is in $N(1), d_{0}^{* *}=$ $d_{1}^{* *}+c_{1}$ if $d_{0} *>d_{1} * *+c_{1}$, and that his decision $d_{0} * *$ will forestall appeals.

Additionally, we claim that

(6) $N(n-j) \subset\left[d_{S}^{*}-\left(c_{n-j}+\ldots+c_{n}\right), d_{S}^{*}+\left(c_{n-j}+\ldots+c_{n}\right)\right]$,

where the inclusion is generally strict. In particular, (6) implies that

$$
N(1) \subset\left[d_{S}^{*}-\left(c_{1}+\ldots+c_{n}\right), d_{S}^{*}+\left(c_{1}+\ldots+c_{n}\right)\right] .
$$

To prove (6), observe that (6) holds for $j=0$, since $N(n)=\left[d_{S}^{*}-c_{n}, d_{S}^{*}+c_{n}\right]$. Then the formula follows by induction: for any $m, N(m)=\left[d_{m}{ }^{* *}-c_{m}, d_{m}{ }^{* *}+c_{m}\right]$; by (5), $d_{m}{ }^{* *}$ is in $N(m+1)$; by the inductive hypothesis, $N(m+1) \subset\left[d_{S}^{*}-\left(c_{m+1}+\ldots+c_{n}\right), d_{S}^{*}+\left(c_{m}+\right.\right.$ $\left.\left.{ }_{1}+\ldots+c_{n}\right)\right]$; hence, $N(m) \subset\left[d_{S}^{*}-\left(c_{m}+\ldots+c_{n}\right), d_{S}^{*}+\left(c_{m}+\ldots+c_{n}\right)\right]$.

We have now established

Proposition 7. Suppose that there are $n$ levels of appeal, where the highest level court has society's preferences.

(a) The initial adjudicator's decision $d_{0}{ }^{* *}$ is the personally best decision in the set $N(1)$ that forestalls appeals at the first level of appeals, so that appeals never in fact occur. 
(b) The adjudicator's decision $d_{0} * *$ in $N(1)$ is connected to the preferences and costs of appeals at all levels through the linking formulas (5). In particular, $N(1)$ must be contained in $\left[d_{S} *-\left(c_{1}+\ldots+c_{n}\right), d_{S} *+\left(c_{1}+\ldots+c_{n}\right)\right] . / /$

The linking formulas relate the adjudicator's decision to the preferences of the highest level appeals court (although the preferences of other appeals courts also play a role), and the influence of the highest court is explicit in the bound $\left[d_{S}^{*}-\left(c_{1}+\ldots+c_{n}\right)\right.$, $\left.d_{S}^{*}+\left(c_{1}+\ldots+c_{n}\right)\right]$ for $N(1)$, which note, is independent of the preferences of the adjudicators below the top level of appeals. This bound means that, the lower are the costs of making appeals, the closer must be the initial decision $d_{0}{ }^{* *}$ to the socially optimal decision $d_{S}{ }^{*}$. Also, as in section 4.1, complete subsidy of appeals (here, at all levels) would lead adjudicators to make the socially optimal decision.

4.5 Uncertainty about the outcome of appeals. It was assumed in the basic model that litigants and adjudicators know the decision $d_{S} *$ that the appeals court would make. If, however, litigant and adjudicator knowledge of what appeals courts would decide is incomplete, then the threat of appeal will be imperfectly calibrated to true deviations from $d_{S}{ }^{*}$, reducing the effectiveness of the appeals process in inducing better decisions.

To examine this point, assume that there is a probability distribution of $d_{S} *$ and that litigants and adjudicators know this distribution but not $d_{S} *$ in a particular case. Since the expected return for litigant 1 from an appeal would be $E\left(d_{S}^{*}\right)$, he would make an appeal when $E\left(d_{S} *\right)-c>d$, and litigant 2 would make an appeal when $E\left(d_{S} *\right)+c<d$, so that appeals would not be made when the decision $d$ is in $N=\left[E\left(d_{S}^{*}\right)-c, E\left(d_{S}^{*}\right)+c\right]$. 
As in the basic model, the adjudicator will select the best decision in $N$, so that appeals will not occur, but the logic behind this conclusion is slightly different from in the basic model. If the adjudicator chooses $d$ outside of $N$ and provokes appeal, his expected utility will be $E u\left(d_{S} *\right)$, but this is strictly less than $u\left(E\left(d_{S}^{*}\right)\right)$ since $u$ is strictly concave. Hence, even if the reversal penalty is zero, the adjudicator is strictly better off choosing $E\left(d_{S} *\right)$, which is in $N$, than provoking appeal. Thus, the adjudicator will choose the best $d$ in $N$, meaning that if $d^{*}<E\left(d_{S}^{*}\right)-c$, he will choose $E\left(d_{S}^{*}\right)-c$, that if $d^{*}$ is in $N$ he will choose $d^{*}$, and that if $d^{*}>E\left(d_{S}^{*}\right)+c$, he will choose $E\left(d_{S}^{*}\right)+c$.

Regarding social welfare, clearly, if the appeals process changes adjudicator behavior, it may or may not raise social welfare in a particular case, since the threat of appeal could result in a decision that is farther away from the socially desirable outcome than the unconstrained choice $d^{*}$ of the adjudicator would be. It is also true that the appeals process might not raise social welfare in an expected sense; see the Appendix for an example. Hence, it cannot be said that the appeals process is socially desirable in the presence of uncertainty about the appeals court decisions. The problem is that adjudicator behavior is influenced not by the true decision that the appeals court would make but by an imperfect perception of it. The conclusions are summarized in the following result.

Proposition 8. Assume that litigants and the adjudicator know only the probability distribution over the socially optimal outcome $d_{S} *$ that would be reached by the appeals court.

(a) The adjudicator's decision $d^{* *}$ is the personally best decision in the set $N$ that forestalls appeals, so that appeals never in fact occur. 
(b) If the unconstrained best choice $d^{*}$ of the adjudicator would not result in an appeal, the adjudicator's choice $d^{* *}$ is $d^{*}$. Otherwise, the adjudicator chooses the closest end point of $N\left(d^{* *}\right.$ is either $E\left(d_{S}^{*}\right)-c$ or $\left.E\left(d_{S}^{*}\right)+c\right)$, a decision that barely forestalls appeals.

(c) The appeals process may or may not raise actual or expected social welfare.// This proposition may be reinterpreted to apply where $d_{S} *$ is fixed and where there is a distribution of appeals court judges identified by their preferred decisions, say $d_{A} *$, and where litigants and adjudicators know only the distribution of $d_{A} *$. Then the above proposition implies (let $d_{A} *$ play the role of $d_{S} *$ ) that an adjudicator will choose the personally best decision in $N=\left[E\left(d_{A}^{*}\right)-c, E\left(d_{A}^{*}\right)+c\right]$. Hence, if appeals court judges are on average unbiased, that is, if $E\left(d_{A}^{*}\right)=d_{S}^{*}$, then $N=\left[d_{S}^{*}-c, d_{S}^{*}+c\right]$, which is to say, adjudicators make decisions as if appeals courts have the social objective. In other words,

Corollary 9. Assume that litigants and the adjudicator know only the probability distribution over the outcome $d_{A} *$ that would be reached by an appeals court but that appeals courts are on average unbiased, $E\left(d_{A} *\right)=d_{S} *$. Then the adjudicator makes the same decision he would if the appeals court has the social objective: the adjudicator chooses the personally best decision $d^{* *}$ in $N=\left[d_{S} *-c, d_{S} *+c\right] . / /$

Thus, for instance, if all judges, trial court adjudicators and appeals court judges, are drawn from the same distribution of judges and the average decision is socially correct, then adjudicators will be just as well controlled by the appeals process as they would be if all appeals court judges had exactly the social preference $d_{s} *$. Of course, this conclusion rests on the assumption that litigants and adjudicators cannot predict which appeals court 
judge they face; if they know who they would face, an adjudicator's decision would be in $N=\left[d_{A}{ }^{*}-c, d_{A}{ }^{*}+c\right]$, and so might be very different from what it is when $N=\left[d_{S}{ }^{*}-c\right.$, $\left.d_{S}^{*}+c\right]$.

4.6 Uncertainty about the making of appeals. Whereas it was assumed in the basic model that adjudicators are able to predict perfectly when appeals would be made, adjudicators may be uncertain when appeals would be made because their knowledge about litigants may be imperfect. This means that appeals may in fact occur, because an adjudicator may misgauge whether a litigant would bring an appeal.

To investigate these issues, suppose that litigants differ in the non-negative cost $c$ of making an appeal but that adjudicators know only the distribution of $c .^{20}$ Let $f(c)$ be the probability density of $c$ for each litigant, where $f$ is continuous, $f(0)=0, f(c)>0$ for $c$ $>0$, and where $F(c)$ is the cumulative distribution function of $c$; assume too that each litigant's $c$ is the same. ${ }^{21}$ If an adjudicator chooses $d<d_{S}^{*}$, there will be an appeal by litigant 1 if $c<d_{S}^{*}-d$; and if an adjudicator chooses $d>d_{S}^{*}$, there will be an appeal by litigant 2 if $c<d-d_{S} *$. Hence, the expected utility of an adjudicator as a function of $d$ is

$$
\left(1-F\left(d_{S}^{*}-d\right)\right) u(d)+F\left(d_{S}^{*}-d\right)\left(u\left(d_{S}^{*}\right)-r\right) \quad \text { for } d<d_{S}^{*},
$$

$$
\begin{array}{ll}
u\left(d_{S}^{*}\right) & \text { for } d=d_{S} * \\
\left(1-F\left(d-d_{S}^{*}\right)\right) u(d)+F\left(d-d_{S}^{*}\right)\left(u\left(d_{S}^{*}\right)-r\right) & \text { for } d>d_{S}^{*} .
\end{array}
$$

Let us show that if $d^{*}<d_{S}^{*}$, then the adjudicator's decision $d^{* *}$ is such that $d^{*}<$ $d^{* *}<d_{S}^{*}$. (If $d^{*}>d_{S}^{*}$, an essentially identical argument shows that $d^{*}>d^{* *}>d_{S}{ }^{*}$.)

\footnotetext{
${ }^{20}$ Alternatively, it could be assumed that adjudicator's have imperfect knowledge of litigant utility functions or of their information about $d_{S} *$.

${ }^{21}$ This might be a fit assumption if, for example, one side's expenditures on appeal would need to be countered by the other. In any case, the assumption is made for convenience and is inessential.
} 
Observe initially that $d^{* *}$ cannot exceed $d_{S} *$, for if $d=d_{S}^{*}$, (8) is just $u\left(d_{S}^{*}\right)$, whereas if $d$ $>d_{S} *$, (8) is less than $u\left(d_{S}^{*}\right)$ (since $u(d)<u\left(d_{S}^{*}\right)$, because $d^{*}<d_{S}^{*}<d$ ). Likewise, $d^{* *}$ cannot lie below $d^{*}$, for (8) is higher at $d^{*}$ than at a lower $d{ }^{22}$ Hence, we can restrict attention to $d$ in $\left[d^{*}, d_{S}^{*}\right]$. For such $d,(8)$ is

$$
\left(1-F\left(d_{S}^{*}-d\right)\right) u(d)+F\left(d_{S}^{*}-d\right)\left(u\left(d_{S}^{*}\right)-r\right),
$$

the derivative with respect to $d$ of which is

$$
f\left(d_{S}^{*}-d\right)\left[u(d)-\left(u\left(d_{S}^{*}\right)-r\right)\right]+\left(1-F\left(d_{S}^{*}-d\right)\right) u^{\prime}(d) .
$$

Note that the first term is the marginal benefit to the adjudicator from raising $d$ : the marginal reduction $f\left(d_{S} *-d\right)$ in the likelihood of appeals multiplied by the utility benefit from avoiding appeal, $u(d)-\left(u\left(d_{S}^{*}\right)-r\right)$. The second term is the expected marginal utility cost. At $d^{*}$, the marginal cost is zero, as $u^{\prime}\left(d^{*}\right)=0$ since $d^{*}$ is optimal, whereas the marginal benefit is positive, so that (9) rises as $d$ is increased, implying that $d^{* *}>d^{*}$. At $d_{S}^{*}$, (10) reduces to $f(0) r+u^{\prime}\left(d_{S}^{*}\right)=u^{\prime}\left(d_{S}^{*}\right)<0$, so that $d^{* *}<d_{S}^{*}$. The explanation is that at $d_{S} *$ there is a first-order utility gain from reducing $d$ but no marginal loss from increasing the probability of an appeal.

Note that the point that there is always some effect of the appeals process on decisions is different from in the basic model, where if $d^{*}$ is in $N$, the appeals process has no influence on adjudicator behavior. Here there is no $N$ known to the adjudicator, there is always a threat of appeal, so always a reason for him to alter the decision somewhat.

${ }^{22}$ At $d<d^{*}$, the probability of appeal is higher than at $d^{*}$. Also $u\left(d^{*}\right)>u\left(d_{S}^{*}\right)$. Hence, we have that $\left(1-F\left(d_{S}^{*}-d\right)\right) u\left(d^{*}\right)+F\left(d_{S}^{*}-d\right)\left(u\left(d_{S}^{*}\right)-r\right)<\left(1-F\left(d_{S}^{*}-d^{*}\right)\right) u\left(d^{*}\right)+F\left(d_{S}^{*}-d^{*}\right)\left(u\left(d_{S}^{*}\right)-r\right)$. Furthermore, since $u(d)<u\left(d^{*}\right)$, we have $\left(1-F\left(d_{S}^{*}-d\right)\right) u(d)+F\left(d_{S}^{*}-d\right)\left(u\left(d_{S} *\right)-r\right)<\left(1-F\left(d_{S} *-\right.\right.$ $d)) u\left(d^{*}\right)+F\left(d_{S}^{*}-d\right)\left(u\left(d_{S}^{*}\right)-r\right)$. Hence, $\left(1-F\left(d_{S}^{*}-d\right)\right) u(d)+F\left(d_{S}^{*}-d\right)\left(u\left(d_{S} *\right)-r\right)<\left(1-F\left(d_{S} *-\right.\right.$ $\left.\left.d^{*}\right)\right) u\left(d^{*}\right)+F\left(d_{S}^{*}-d^{*}\right)\left(u\left(d_{S}^{*}\right)-r\right)$, which is that (8) is lower at $d$ than at $d^{*}$. 
Because the adjudicator chooses $d^{* *}$ different from $d_{S}{ }^{*}$, there will be a positive probability of appeals, and costs borne in the process, which is another difference from the basic model. The expected costs of appeals are given by

$$
F\left(\left|d_{S}^{*}-d^{* *}\right|\right)\left[2 E\left(c|c<| d_{S} *-d^{* *}\right)\right],
$$

since $F\left(\mid d_{S}{ }^{*}-d^{* *}\right)$ is the likelihood of appeal and $E\left(c|c<| d_{S}^{*}-d^{* *} \mid\right)$ are the mean costs of the litigant who brings an appeal.

Observe also that the higher is the penalty $r$ for reversal, the closer will be the adjudicator's decision to $d_{S}{ }^{*}$. ${ }^{23}$ This also contrasts with the basic model, where $r$ did not influence the decision; since appeals actually occur and result in reversals, the penalty for them must matter to adjudicator behavior. Also, raising $r$ increases social welfare for two reasons. First, raising $r$ directly enhances social welfare because it makes $d$ closer to $d_{S} *$ (it increases $d$ in the case where $d^{* *}<d_{S} *$ and decreases $d$ in the other case). Second, raising $r$ indirectly raises social welfare by making appeals less likely, and thus reduces the expected resource cost of appeals given by (11).

Because the appeals process results in the occurrence of costly appeals, the question arises whether the appeals process might be socially undesirable (it is obvious that it may be desirable, if the cost of appeals is sufficiently low). The answer is that the appeals process may be undesirable, the reason being, in essence, that the decision of a litigant whether or not to bring an appeal involves a comparison of the private cost of an

\footnotetext{
${ }^{23}$ The first order condition determining $d$ is, from $(10), f\left(d_{S}{ }^{*}-d\right)\left[u(d)-\left(u\left(d_{S} *\right)-r\right)\right]+\left(1-F\left(d_{S} *\right.\right.$ $-d)) u^{\prime}(d)=0$. This is of the form $z(d, r)=0$ and implicitly determines $d=d(r)$. If $z(d(r), r)=0$ is differentiated with respect to $r$, we obtain that $d^{\prime}(r)=-z_{r} / z_{d}$, but $z_{d}<0$ (the second-order condition for a maximum), and $z_{r}$ is $f\left(d_{S}{ }^{*}-d\right)>0$, so that $d^{\prime}(r)>0$. Note too that if the reversal penalty $r$ were not a constant but an increasing function of the deviation $\left|d_{S}{ }^{*}-d\right|$, there would be an additional incentive for the adjudicator to choose a decision closer to $d_{S}{ }^{*}$.
} 
appeal versus the private benefit, whereas the social comparison is different. ${ }^{24}$ To demonstrate that the appeals process might be socially undesirable, observe that the behavior of litigants and adjudicators is determined by (8) and the probability distribution $f$ over $c$. This implies, among other things, that (8) and $f$ determine the adjudicator's decision $d^{* *}$ and the expected costs of appeal, (11). The nature of the social welfare function $w(d)$ does not affect outcomes as long as $w(d)$ is maximized at $d_{S} *$. Now consider a family of social welfare functions $\lambda w(d)$ where $\lambda$ is a positive parameter. They are all maximized at the same decision, $d_{s} *$, so that the behavior of litigants and adjudicators is the same regardless of $\lambda w(d)$. But as $\lambda$ becomes small, it must become socially undesirable to employ the appeals process because the welfare gain from the change in the adjudicator's decision, $\lambda\left[w\left(d^{* *}\right)-w\left(d^{*}\right)\right]$, will be dominated by the cost of the process, $F\left(\left|d_{S}^{*}-d^{* *}\right|\right)\left[2 E\left(c|c<| d_{S}{ }^{*}-d^{* *} \mid\right)\right]$, which does not depend on $\lambda$.

To summarize the various findings of this section, we state

Proposition 10. Assume that adjudicators know only the probability distribution of the cost $c$ of making an appeal among litigants, so do not know whether an appeal would be made.

(a) The adjudicator's decision $d^{* *}$ lies strictly between his unconstrained best choice $d^{*}$ and the socially optimal decision $d_{S} *$, and the higher is the reversal penalty $r$, the closer is $d^{* *}$ to $d_{S} *$.

(b) The probability of appeals is positive and the appeals process thus generates positive expected costs.

${ }^{24}$ This point is an illustration of the more general point that the private incentives to use the legal system differ from the social ones; see generally Shavell (1997). 
(c) The appeals process may or may not be socially desirable (because its benefit in altering adjudicator decisions may or may not outweigh its expected costs).//

4.7 Discretion of appeals courts whether to hear appeals. To this point, it has been assumed that appeals courts consider any case that is appealed to them, whereas in fact appeals courts sometimes have discretion whether or not to hear an appeal. ${ }^{25}$ Here discretion is investigated using the assumptions of the last section, where appeals are sometimes brought. The possible value of discretion in this context is, as mentioned in the introduction, that the appeals court can refuse to hear cases for which the social benefit is outweighed by the cost. This can help to counter the problem noted in the last section that, due to the cost of the appeals process, the appeals process might not be socially desirable.

To be specific, assume that the appeals court can costlessly decide not to review a case that has been appealed, and that if the case is not heard, no costs will be borne by the litigants. $^{26}$ The appeals court will reject a case if and only if

$$
w\left(d_{S}^{*}\right)-w(d)<2 c
$$

For given that an appeal has been brought, social welfare will fall if the appeal is heard when (12) holds, since the left side is the change in social welfare from the decision if the appeal is heard and the right side is the cost to the two litigants of an appeal. ${ }^{27}$ Hence,

\footnotetext{
${ }^{25}$ This is often true at the second level of appeals, and notably at the Supreme Court of the United States.

${ }^{26}$ It would be straightforward to add the assumption that the appeals court must bear a cost to investigate an appeal and/or that the litigant must bear a cost for the case to be considered for appeal, and then an additional cost if it is heard. These assumptions, while realistic, are not needed to develop the points of importance in this section.

${ }^{27}$ That the appeals court takes social costs of appeals into account here is consistent with its maximizing only $w(d)$ in previous sections, since before it did not have the opportunity to decide whether or not to hear an appeal. Note too that it is consistent with what has been assumed (see the remarks at the
} 
appeals will be brought and heard if and only if two conditions hold: that $d$ is not in $N=$ $\left[d_{S}^{*}-c, d_{S}^{*}+c\right]$; and that (12) does not apply, that is, that

(13) $w\left(d_{S}^{*}\right)-w(d) \geq 2 c$

is true. Note that it may well be that (12) prevents appeals that would otherwise be brought, for it is quite possible that, for instance, $d<d_{S}{ }^{*}-c$ yet (12) holds. (That is, it is quite possible that $\left.\left(w\left(d_{S} *\right)-w(d)\right) / 2<c<d_{S} *-d .{ }^{28}\right)$

To the degree that (12) prevents appeals from being brought, discretion must raise social welfare given the decision of the adjudicator. However, because discretion may reduce the probability of appeal, it may lower the incentive of adjudicators to conform their decisions to $d_{S} *$ and so may indirectly reduce social welfare. This raises the question whether discretion could be socially undesirable. Examples (see the Appendix) show that discretion may lower social welfare as well as raise it. (Note that it is not paradoxical that discretion might lower social welfare, for the appeals court decides whether to hear appeals on the basis of (12), which is to say, it maximizes social welfare only in an ex post sense.) The main conclusion about discretion is

Proposition 11. Under the assumptions of Proposition 10, suppose that the appeals court has discretion to decide whether or not to hear an appeal. Then given any decision of the adjudicator, appeals court discretion can only lead to an increase in social welfare. But because the adjudicator's decision generally changes due to appeals court

end of section 2) that the appeals court maximizes social welfare in an ex post sense; the appeals court is assumed not to be able to commit to a policy of rejecting appeals.

${ }^{28}$ Not only is this possibility formally apparent, since no restrictions have been imposed on $w$ other than that it is strictly concave, there are economic explanations for the possibility. An important one is that social welfare may depend on damages $d$ because of the incentives that payment of damages would create to prevent harm. These incentives might be weak (for example, there might be little that can be done to prevent harm), implying that $w$ would not be very sensitive to $d$. In such a case, the effect of $d$ on $w$ might be less than the change in $d$, which is what the litigants care about. 
discretion, social welfare may or may not increase as a consequence of appeals court discretion.//

\section{Concluding Remarks}

(a) The main point elaborated in this article - that the threat of appeal leads adjudicators to make decisions that conform more closely to the socially optimal decision than would otherwise be the case - rests on the assumption that the appeals court would tend to right incorrect decisions, in other words, that the appeals court embodies the social interest. Yet this is a fiction in a strict sense, since appeals courts must in fact be comprised of individuals who, like the lower court adjudicators of the model studied here, may have their own preferences. Hence, the problem of policing adjudicator behavior is recapitulated at the appeals court level. (Indeed, if the appeals court judge has the same preferences as the trial court judge, the appeals process is valueless. ${ }^{29}$ )

This problem of who guards the guardians is ameliorated in a number of ways going outside the analysis of this article. In particular, society may invest special effort in selecting appeals court judges to ensure that their preferences are aligned with society's, it may have appeals court judges decide in panels (so as to offset each others' differences in preferences), and it may induce appeals court judges to write opinions explaining their decisions (reducing their ability to contravene social preferences). The problem that appeals court judges have their own preferences is also reduced in two ways studied in the analysis. First, as noted in Corollary 9, if appeals court judges' preferences are socially desirable on average and trial court judges do not know which appeals court

${ }^{29}$ If the appeals court adjudicator has the same utility function $u(d)$ as the trial court adjudicator, the latter would choose his personally optimal decision $d^{*}$ and no appeals would be made, for they would not be reversed - thus the outcome would be the same as in the absence of an appeals process. 
judge they will draw in a case, then the appeals process will function well. Second, as shown in section 4.4, if there are tiers of appeals with the adjudicator at the topmost level having the social interest, the social decisional preferences will be transmitted (to a degree reflecting appeals costs at all levels, among other factors) down to the level of the trial court; thus by appropriate selection of adjudicators only at the highest levels of appeal, society has at its disposal a relatively cheap way of helping to ensure that decisionmaking at the level of trial courts is guided by its preferences.

(b) At the outset of this article, it was suggested that the appeals process might be viewed in a general light, as a means of reducing an agent's deviation from optimal behavior in a principal and agent setting. To amplify, the reason that an agent's behavior differs from what would be mutually best for him and the principal involves, of course, the principal's lack of information, either about the agent's information set or about his action. ${ }^{30}$ Implicit in the assumption that the principal lacks information is that the cost of obtaining the information about the agent is too high to make that worthwhile. In some circumstances, however, an analogue to the appeals process could operate to cheaply reduce the agency problem. This might be so when three conditions hold: there is a person who is in a natural position to know the agent's information set or to observe his action; this third person could credibly report his observation to the principal; and the third person would have a motive to do so, notably if he would suffer from the agent's deviations. ${ }^{31}$ The threat of such a third person making a report to the principal could

\footnotetext{
${ }^{30}$ See, for example, the articles collected in Pratt and Zeckhauser (1991).

${ }^{31}$ For example, an employee (the third person) working under a manager (the agent) might observe the manager shirking (for instance, showing up late), might be able to convey this information credibly to a higher level party in the firm (representing the principal), and might suffer due to the shirking (have to work harder while the manager is absent). However, it is evident that one of the three conditions often would not hold. Relevant information about the agent might not be known by a third person (for
} 
make the agent behave better, and to the degree that the agent acted so as to forestall a report, this appeals-like process would not involve cost. Explicit investigation of when these conditions might hold (or could be engendered) in a principal and agent framework might be worthwhile. ${ }^{32}$

instance, there might be no one who is privy to the manager's information set, such as his menu of business opportunities); or if relevant information is known by a third person, it might not be easy to credibly convey (it might be difficult to establish that the manager often showed up late, or what the manager's business opportunities were); or the third person might not have a motive to make a report (a manager might find a way to punish the third person for having made a report).

${ }^{32}$ Among the issues of interest in such an investigation is that of possible collusion between the agent and a third person for him not to make a report to the principal (but how would an agreement between them be enforced?). An article that deals with these issues in the specific context of the government procurement process is Marshall, Meurer, and Richard (1994), in which procurement officers are viewed as agents of the government, the principal, and firms that do not obtain contracts may protest to a government board of contract appeals. 


\section{References}

Becker, Gary S. 1968. Crime and Punishment: An Economic Approach. Journal of Political Economy. 76: 169-217.

Cameron, Charles M., and Lewis A. Kornhauser. 2004. Appeals Mechanisms, Litigant Selection, and the Structure of Judicial Hierarchies. In Institutional Games and the Supreme Court, Jon Bond, Roy Flemming, and James Rogers (editors). University of Virginia Press, Charlottesville.

Daughety, Andrew F., and Jennifer F. Reinganum. 2000. Appealing Judgments. Rand Journal of Economics. 31:502-25.

-----. 2004. Speaking Up: A Model of Judicial Dissent and Discretionary Review. Vanderbilt University.

Dalton, Harlon Leigh. 1985. Taking the Right to Appeal (More or Less) Seriously. Yale Law Journal. 95: 62-107.

Herzog, Peter E., and Delmar Karlen. 1982. Attacks on Judicial Decisions, Chapter 8, Vol. XVI, Civil Procedure, International Encyclopedia of Comparative Law. J.C.B. Mohr, Tubingen and Martinus Nijhoff Publishers, The Hague.

Iossa, Elisabetta, and Giuliana Palumbo. 2004. Partisans and Discretion. Brunel University.

Levy, Gilat. 2003. Careerist Judges. London School of Economics, forthcoming Rand Journal of Economics.

Marshall, Robert C., Michael J. Meurer, and Jean-Francois Richard. 1994. Curbing Agency Problems in the Procurement Process by Protest Oversight. Rand Journal of Economics. 25: 297-318.

Mertens, Jacob, Jr. 1994. The Law of Federal Income Taxation, vol. 13. West Group, St. Paul.

Platto, Charles (editor). 1992. Civil Appeal Procedures Worldwide. Graham and Trotman, Boston, International Bar Association Series.

Pratt, John W. and Richard J. Zeckhauser (editors). 1991. Principals and Agents: The Structure of Business. Harvard Business School Press, Boston.

Pound, Roscoe. 1941. Appellate Procedure in Civil Cases. Little Brown, Boston. 
Scott, William G. 1965. The Management of Conflict. R. D. Irwin, Homewood, Illinois.

Shavell, Steven. 1995. The Appeals Process as a Means of Error Correction. Journal of Legal Studies. 24: 379-426.

-----. 1997. The Fundamental Divergence Between the Private and the Social Motive to Use the Legal System. Journal of Legal Studies. 26(2): 575-612.

Spitzer, Matthew, and Eric Talley. 2000. Judicial Auditing. Journal of Legal Studies. 24 (2, Pt. 1): 649-684.

Stith, Kate. 1990. The Risk of Legal Error in Criminal Cases: Some Consequences of the Asymmetry in the Right to Appeal. University of Chicago Law Review. 57: 1-61.

Weiler, Paul C. and Gary R. Roberts. 1993. Cases, Materials, and Problems in Sports and the Law. West Publishing, St. Paul. 


\section{Appendix}

Proposition 8 . The only point that needs to be addressed is why the appeals process might lower expected social welfare, which we show by providing an example. Suppose that there are two equally likely social welfare functions: $w_{1}(d)=-(d-1)^{2}$ and $w_{2}(d)=-\epsilon(d-2)^{2}$, where $\epsilon$ will be chosen to be small. Observe that if the social welfare function is $w_{1}(d)$, then the socially best decision $d_{S} *$ is 1 , and if the social welfare function is $w_{2}(d)$, then $d_{S} *$ is 2 . Consequently, $E\left(d_{S}^{*}\right)=1.5$. Let $c=.01$. Also, assume that $u(d)=-(d-1)^{2}$, so that the unconstrained choice of the adjudicator $d^{*}$ would be 1 . We know from section 4.5 that, given the appeals process, the adjudicator would choose $d^{* *}=E\left(d_{S}^{*}\right)-c=1.5-.01=1.49$, since this exceeds $d^{*}=1$. Expected social welfare is therefore $-\left[.5(1.49-1)^{2}+.5 \epsilon(1.49-2)^{2}\right]=-[.12+.13 \epsilon]$. However, if there were no appeals process, the adjudicator would choose $d^{*}=1$, and expected social welfare would be $-[.5(0)+.5 \epsilon]=-.5 \epsilon$. Clearly, if $\epsilon$ is sufficiently small, $-.5 \epsilon>-[.12+.13 \epsilon]$, so that expected social welfare is higher in the absence of the appeals process.

Proposition 11. Two examples need to be supplied, one where discretion raises social welfare and one where it lowers social welfare. These examples involve discrete distributions over $c$; it will be obvious that continuous approximations of them could be constructed in which discretion has the same effect on social welfare.

Example where discretion raises social welfare. Let the adjudicator's utility be $(d-2)^{2}$, so that his unconstrained preferred decision $d^{*}$ is 2 , and let social welfare be 
$-.001(d-10)^{2}$, so that the socially preferred decision of the appeals court is 10 . Let $r=0$ and let there be two possible costs of making and defending an appeal: $c_{1}=1$, with probability $.1 ; c_{2}=2$, with probability .9 .

No appeals court discretion: The adjudicator will obviously not want to choose $d$ $>10$, so we can consider $d \leq 10$. Observe that a $c_{1}$ will appeal such a decision if and only if $d<9$ and that a $c_{2}$ will appeal such a $d$ if and only if $d<8$. Hence, the adjudicator will in fact choose either 8 or 9: if $d<8$, there will definitely be an appeal, so $d$ will equal 10, making the adjudicator worse off than if $d=8$; the adjudicator would not choose $d$ in $(8,9)$, for choosing 8 dominates any such $d$ because litigant behavior is the same and the adjudicator prefers 8 to a higher $d$; likewise he would not choose a $d$ in $(9$, 10]. It is readily verified that the adjudicator would choose 8 instead of 9: at $d=8, c_{1} \mathrm{~S}$ would appeal but not $c_{2}$ s, so the adjudicator's expected utility would be $-\left[.1(10-2)^{2}+\right.$ $\left..9(8-2)^{2}\right]=-38.8$; at $d=9$, no one would appeal, so the adjudicator's utility would be $(9-2)^{2}=-49$. Thus, the adjudicator chooses $d=8$ and appeals are made with probability .1 by $c_{1}$ s. Social welfare is $-\left[.1(2)+.9(.001)(10-8)^{2}\right]=-.2036$, since when appeals are made social welfare from the decision is 0 but litigation costs of 2 are incurred, and since when appeals are not made $d$ is 8 .

Appeals courts have discretion: In this case, any appeal would be rejected, since the maximum possible social value of an appeal is $.001(10-2)^{2}=.064$ and the minimum cost is 2 . Since there can be no threat of appeal, the adjudicator will choose $d=2$, there will be no appeals, and social welfare will be $-.001(10-2)^{2}=-.064$.

Effect of discretion: Giving appeals courts discretion raises social welfare, from .2036 to -.064 . The reason is that it results in the rejection of appeals whose social costs 
outweigh social benefits. The resulting saving in social costs of appeals outweighs the undesirable effect that discretion has on the adjudicator incentives, which here is to reduce the decision $d$ from 8 to 2 .

Example where discretion lowers social welfare. Let the adjudicator's utility again be $-(d-2)^{2}$, so that his unconstrained preferred decision $d^{*}$ is 2 , and let social welfare be $-(d-10)^{2} / 3$, so that the socially preferred decision of the appeals court is 10 . Let $r=0$ and let there be three possible costs of making and defending an appeal: $c_{1}=1$, with probability $.1 ; c_{2}=2$, with probability .5 ; and $c_{3}=3$ with probability .4 .

No appeals court discretion: The adjudicator will not want to choose $d>10$, so we can consider $d \leq 10$. A $c_{1}$ will appeal such a decision if and only if $d<9$, a $c_{2}$ will appeal such a $d$ if and only if $d<8$, and a $c_{3}$ will appeal such a $d$ if and only if $d<7$. Hence, the adjudicator will in fact choose either 7, 8, or 9: if $d<7$, there will definitely be an appeal, so $d$ will equal 10, making the adjudicator worse off than if $d=7$, since then $c_{3}$ S will not appeal, making the adjudicator better off; the adjudicator would not choose $d$ in $(7,8)$, for choosing 7 dominates any such $d$ because litigant behavior is the same and the adjudicator prefers 7 to a higher $d$; likewise he would not choose a $d$ in $(8,9)$ or in $(9,10]$. It is readily verified that among 7,8 , and 9 , the adjudicator would choose 8: at $d=7, c_{2} \mathrm{~S}$ and $c_{1} \mathrm{~S}$ would appeal but not $c_{3} \mathrm{~S}$, so the adjudicator's expected utility would be $-\left[.6(10-2)^{2}+.4(7-2)^{2}\right]=-48.4$; at $d=8, c_{1}$ S would appeal but not $c_{2} \mathrm{~S}$ and $c_{3}$ s, so the adjudicator's expected utility would be $-\left[.1(10-2)^{2}+.9(8-2)^{2}\right]=-38.8$; at $d=9$, no one would appeal, so the adjudicator's utility would be $-(9-2)^{2}=-49$. Thus, what happens is that the adjudicator chooses $d=8$ and appeals are made with probability .1 by $c_{1}$ s. Social welfare is $-\left[.1(2)+.9(10-8)^{2} / 3\right]=-1.4$, since when appeals 
are made social welfare from the decision is 0 but litigation costs of 2 are incurred, and since when appeals are not made $d$ is 8 .

Appeals courts have discretion: In this case, again, the adjudicator will not choose $d>10$, and will, by essentially the argument given above, not choose $d$ in $(7,8)$, $(8,9)$, or $(9,10]$. If the adjudicator chooses $d=9$, as before, no one would appeal, so the issue of discretion is moot, and the adjudicator's utility would be -49 . If the adjudicator chooses $d=8$, whereas before $c_{1}$ s would appeal, these appeals would be rejected by the appeals court, since the social value of such an appeal would be $(10-8)^{2} / 3=4 / 3$, whereas the social cost of the appeal (for both parties) is 2 . Hence, the utility of the adjudicator would simply be $-(8-2)^{2}=-36$. If the adjudicator chooses $d=7$, the $c_{1} \mathrm{~s}$ would wish to appeal and their appeal would be accepted, since its social value would be $-(10-7)^{2} / 3=3$, whereas its social cost is 2 . However, although the $c_{2}$ S would also want to make an appeal, their appeal would be rejected, since its social cost is $4>3$. Hence, the adjudicator's expected utility would be $-\left[.1(10-2)^{2}+.9(7-2)^{2}\right]=-28.9$. Thus $d=$ 7 is superior to 8 . In fact, the adjudicator would choose $d=6.54$, for he can reduce $d$ to this level without provoking an appeal by the $c_{2}$ s that would be accepted by the appeals court: at $d=6.54$, the social value of an appeal is 4 , just equal to the social cost. At this $d$, only the $c_{1} \mathrm{~S}$ would appeal, their appeals would be accepted, and the expected utility of the adjudicator would be $-\left[.1(10-2)^{2}+.9(6.54-2)^{2}\right]=-24.95$. (The adjudicator could reduce $d$ to as low as 5.76 without provoking an appeal by the $c_{3}$ s that would be accepted by the appeals court: at $d=5.76$, the social value of an appeal is 6 , equal to the social cost. At this $d$, the $c_{1} \mathrm{~S}$ and $c_{2} \mathrm{~S}$ would appeal, their appeals would be accepted, and the expected utility of the adjudicator would be $-\left[.6(10-2)^{2}+.4(5.76-2)^{2}\right]=-44.06<$ 
Effect of discretion: It has been seen that granting appeals courts discretion leads to a lower level of social welfare, -24.95 as opposed to -1.4 . The explanation is as indicated in section 4.7. Appeals courts with discretion do not accept appeals when $d=$ 8 and the cost is 4, since the social benefit from such appeals is less than the cost, raising social welfare in itself. But the consequence of this behavior, and of discretion in regard to other appeals, is to dilute the adjudicator's incentive to conform his decision to the socially optimal one of 10 , and he in fact lowers his decision from 8 , in the absence of discretion, to 6.54. This change in his behavior leads to the reduction in social welfare. 